\title{
Examining the Life Quality and Depressive State of Amputees in Terms of Some Variables
}

\author{
Mehmet Yazıcı ${ }^{1, *}$, M. Yalçın Taşmektepligil ${ }^{2}$ \\ ${ }^{1}$ School of Physical Education and Sports, Erzincan Binali Yıldırım University, Turkey \\ ${ }^{2}$ Yaşar Doğu Faculty of Sports Science, Ondokuz Mayıs University, Turkey
}

Copyright $(\mathrm{C} 2018$ by authors, all rights reserved. Authors agree that this article remains permanently open access under the terms of the Creative Commons Attribution License 4.0 International License

\begin{abstract}
This research aimed to determine whether the life quality of amputees was a significant predictor of their depression levels and whether there was a significant difference between the life quality levels and depression of amputee athletes and those leading sedentary lifestyles according to their marital status and disabled limbs. The data were collected from 202 amputees including 76 athletes and 126 sedentary. Personal Information Form, a 27-item Short Form Life Quality Scale, and Beck Depression Inventory were used as the data collection tools. The internal consistency coefficient calculated for the Life Quality Scale was 0.90 , and it was 0.89 for Beck Depression Inventory in the study. The results of simple linear regression analysis performed for determining the life quality's strength of predicting depression revealed that the life quality scores of amputees were a negative significant predictor of their depression scores. It was determined that married individuals had significantly higher life quality scores and lower depression scores when compared to single individuals. In terms of the disabled limb, the difference between the life quality scores of individuals with arm-leg and foot-leg amputation was found to show a significant difference rather than those with leg amputation. In addition, it was noticed that the depression scores of the individuals with foot and leg amputation were significantly higher than those with arm amputation. Consequently, it was possible to mention that life quality affected depression, and sport was an important instrument for increasing the life quality and decreasing the depression levels of amputees. Appropriate sportive activities should be emphasized to achieve desired life quality levels and relieve depression of disabled people.
\end{abstract}

Keywords Amputee, Football, Depression, Quality of Life

\section{Introduction and Objective}

In today's world of science and technology, technological developments facilitate the lives of human beings in many areas. These developments and innovations present in the lives of all people for meeting the requirements offer remarkable opportunities to relieve the disadvantages of people with disabilities and to improve their life quality. The developments that are considered as a positive change in human life can actually be a basic requirement for people with disabilities and can make a significant contribution upon their lives changing their lives. The increase at industrialization and urbanization rate in parallel with technological developments causes living conditions to become increasingly stable. As result of this, increase has appeared on the prevalence of life-threatening problems such as stress, anxiety, panic attack, psychological disorder, depression, and hypokinetic diseases. According to the reports of World Health Organization, sedentary life is ranked the 4th, before obesity, in the list of health-related risks. Every year, 3.5 million people around the world lose their lives because of inactivity. Many more people suffer from chronic diseases and maintain their lives unhappily. Inactivity has now become a serious problem in Turkey. In fact, we have lived in a period when $40 \%$ of the population lives sedentary lives, children become increasingly inactive, and health problems such as obesity negatively affect the quality of life [1]. It is possible to say that these aforementioned problems have been experienced or felt more intensely by disabled people when compared to normal individuals.

Studies have indicated that disabled people's difficulties of using technology lead more stress and depression, and also their levels of anxiety are higher [2]. These effects are seen not only in disabled individuals but also in their families. It has been reported that families of disabled individuals experience mental problems such as somatic complaints, depression and anxiety disorder more frequently than the families who do not have children with disabilities [3].

Today, disabled citizens have been struggling with the inadequacies of the public services as well as their lack of physical and mental abilities while meeting the needs of 
normal life. This causes disabled people to have more negative feelings of life such as stress and depression affecting them. Stress caused by the technology and social life stress caused by being disabled has negative effects on the lives of disabled people. Individuals with disabilities constantly encounter with other obstacles in the social environment (school, street, sports areas, etc.). Therefore, because the disability is a social problem, it also becomes a problem of the society [4]. Disabled individuals are the most marginal parts of the world's societies and maintain lives with lower quality when compared to non-disabled individuals. For disabled people as well as non-disabled individuals, exercise or sports seem to be a therapeutic prescription for getting rid of internal and external adversities and raising the quality of life.

With a history dating back to the beginning of human history, sport draws attention as an important part of social life. Due to improving economic conditions, industrialization, intense urbanization, increase at leisure time and personal health concerns of individuals, the sports has begun to take an important place in everyday life through gaining new meanings. Doing sports regularly prevents negative emotions, improves physical conditions, and contributes upon overall health. Besides doing professionally, the sports done to have a healthy lifestyle and raise the quality of life has an important place in the lives of individuals.

The sports provide people with disabilities to have the opportunity to participate in physical activities, strength their personality development and self-confidence, and help them adapt into the social life. Sports and physical activities are benefited as means of physical, mental, emotional and social development in disabled people due to their rehabilitative and therapeutic effects. Participation of disabled people in sports activities draws the attention of the society to disabled people, and negative attitudes and behaviors can be changed in this way. Through sports activities, the disabled people learn about co-operation, sharing and interpersonal rules in society. Such activities raise the life quality of disabled people and create a social environment in which they can realize themselves with an athletic identity. Sport is recommended for both disabled and non-disabled people in terms of connecting them to life throughout their lives [5].

Sports can open a new window for people with disabilities who already experience many obstacles in their lives and live with the stress created by these obstacles. No matter what type or degree of the disability is, exercising and participating in sports activities give pleasure to individuals. The pleasure of exercising is an important tool in meeting the needs of enjoyment and achievement of the individual and increases the motivation of life [6]. When we look at the recent studies on the quality of life, it can be noticed that many researches have demonstrated sports' improving the quality of life in people with disabilities [7,8,9]. In order for amputees, who are categorized under the group of physical disabilities within the disability groups, to increase the quality of their lives, to lead more productive lives and to participate in social life more actively, they need to engage in sports activities. Sport promotes the physical, mental and social development of disabled individuals, and contributes to their social adaptation [10]. Sports should be used as an instrument to support the mental conditions of disabled individuals. Sports will be good for many mental disorders of disabled people [11]. Sport is now an important instrument for raising the life quality of not only disabled individuals but all individuals.

With this study, it was aimed to obtain data related to the social life problems of the amputee individuals who did and did not do sports, to define their problems, to identify new approaches to solve their problems, and to search for the efforts to give positive value to society's understanding of disabled people.

Taking this as a starting point, answers to the following questions were sought in this study:

- Is the life quality of amputees a significant predictor of their depression levels?

- Is there a significant difference between the life quality and depression levels of amputees and sedentaries in terms of their marital status?

- Is there a significant difference between the average life quality scores of amputees and sedentaries in terms of their disabled limbs?

Is there a significant difference between the average life quality and depression scores in terms of being amputee or maintaining sedentary lifestyles?

\section{Material and Method}

Descriptive and relational screening model was used in this study aiming to reveal the relationship between life quality and depression levels of the amputees doing and not doing sports. The screening models aim to describe an existing situation as it exists [12]. Descriptive screening models are research approaches that aim to describe a past or present situation as it is. The subject, individual or object studied are tried to be defined as it is under the original conditions. No attempt is made to alter or influence them in anyway. Relational screening models aim to determine the presence and/or degree of change between two or more variables [13].

\section{Participants}

The study group of the research included 202 amputees who were playing and not playing football in Ankara, İstanbul, and İzmir, provinces. In this study, the basic reason for preferring football for carrying out the research 
was football's being the dominant type of sport among male individuals in terms of both its implementation and watching Distribution of the amputee individuals in the study group in terms of their being athletes or sedentary and their marital status and disabled limb was presented in Table 1 .

Table 1. Number and distribution percentages related to the participants

\begin{tabular}{|c|c|c|c|}
\hline Variables & & N & Percentage \\
\hline Status & Athlete & 76 & 37,6 \\
\hline & Sedentary & 126 & 62,4 \\
\hline Total & & $\mathbf{2 0 2}$ & $\mathbf{1 0 0}$ \\
\hline Marital Status & Married & 72 & 35,6 \\
\hline & Single & 123 & 60,9 \\
\hline & Not Mentioned & 7 & 3,5 \\
\hline Total & & $\mathbf{2 0 2}$ & $\mathbf{1 0 0}$ \\
\hline Disabled Limb & Hand & 7 & 3,5 \\
\hline & Arm & 15 & 7,4 \\
\hline & Foot & 108 & 53,5 \\
\hline & Leg & 72 & 35,6 \\
\hline & & $\mathbf{2 0 2}$ & $\mathbf{1 0 0}$ \\
\hline Total & & &
\end{tabular}

According to Table 1, the number of athletes in the study group was significantly higher rather than the number of sedentary individuals. Because there was no female amputee football league in Turkey, all participants were males. Furthermore, amputee male individuals under 18 were excluded from the study because they could not participate into a scientific study without taking the permission of their families in Turkey.

\section{Data Collection Tools}

Three data collection tools were used in this study. These were Personal Information Form, Beck Depression Inventory and Short Form of Life Quality Scale developed by World Health Organization.

\section{Beck Depression Inventory}

Beck Depression Inventory (BDI) was developed by Beck et al. [14], and adapted into Turkish by Hisli [15]. There are 21 items including 4 choices in BDI. The scale is mon0-dimensional, and the highest score possible to be taken is 63 , and the lowest score is zero. High score indicates high depression level, and low score indicates low depression level. Internal consistency coefficient of the inventory was calculated to be 0.89 in the study. This inventory was used for determining the depression of the participants.

\section{Short Form of Life Quality Scale}

For determining the life quality of the participants, Whoqol-Bref Inventory developed by World Health Organization in 1980 and adapted into Turkish by Fidaner et al. through carrying out the studies on its validity and reliability was used in the study [16]. The scale was on 5-point Likert type and included 27 items. Four of these were reverse items. The scale had four sub-dimensions as Physical Health, Psychological Health, Social Relationships and Environment. The highest score possible to be taken from the scale was 135, and the lowest score was 27 . High score indicated high quality of life, and low score indicated the low life quality. The analyses on this scale were performed regarding the total score. Internal consistency coefficient of the scale was 0.90 in this study.

\section{Statistical Analysis}

The data were obtained from the questionnaires performed to the participants in amputee football clubs and associations regarding their voluntariness. During this process, the participants were asked to fill in the questionnaires considering their last fifteen days. The participants filled in the questionnaire in approximately 10 minutes. While filling in the questionnaires, the participants were prevented to influence each other.

Simple linear regression analysis was performed in order to answer the research question of "Is the life quality of amputees a significant predictor of their depression levels?" Independent samples t-test was performed for determining whether there was a significant difference between life quality and depression levels of the participants in terms of their marital status. Independent samples t-test was also performed to specify whether there was a significant difference between the averages. Due to not providing the conditions of parametric test, Kruskal-Wallis H-test was performed for determining the significant difference between life quality and depression level line averages of amputee athletes and sedentary individuals in terms of the disabled limb; and Mann-Whitney U-test was used to fing the source of the difference when available.

\section{Findings}

The findings obtained for determining the relationship between the quality of life and depression levels of amputees who did and did not do sports were presented in the following tables. 
Table 2. The results of simple linear regression analysis of life quality's strength of predicting depression

\begin{tabular}{|c|c|c|c|c|c|}
\hline & & Unstandardized Coefficients & & Standardized Coefficients & \\
\hline Model & $\beta$ & S. Error & B & T & $p$ \\
\hline Constant & 47.906 & 3.376 & & 14.191 & $0.001^{*}$ \\
\hline Quality of life & -.418 & .039 & -0.607 & -10.795 & $0.001^{*}$ \\
\hline
\end{tabular}
R:60 R ${ }^{2}: 0.368 \quad F_{1-200}: 116.530, \quad \mathrm{p}<0.01 \quad{ }^{*} \mathrm{P}<0.01$

Table 2 presented the results of simple linear regression analysis of life quality's strength of predicting depression. The results of the one-way ANOVA test generally indicated that the established regression model was significant $\left(\mathrm{F}_{1200}: 116.530, \mathrm{p}<0.01\right)$. The results of the analysis demonstrated that life quality of amputees was a significant predictor of their depression levels $(\mathrm{R}=0.607$, $\mathrm{R}^{2}=0.368$ ). It was possible to mention that as life quality of amputees increased the level of depression they experienced decreased, and $36.8 \%$ of the variance in depression level was due to the quality of life.

Table 3. Independent Sample T-test Results Related to the Average Scores of Life Quality of Amputees According to their Marital Status

\begin{tabular}{|c|c|c|c|c|c|c|}
\hline $\begin{array}{c}\text { Marital } \\
\text { Status }\end{array}$ & $\mathrm{N}$ & $\bar{X}$ & $\mathrm{Ss}$ & $\mathrm{Sd}$ & $\mathrm{t}$ & $\mathrm{P}$ \\
\hline Married & 72 & 91.15 & 10.70 & 193 & 3.902 & $0.001^{*}$ \\
\hline Single & 123 & 83.10 & 15.48 & & & \\
\hline $\mathrm{P}<0.01$
\end{tabular}

Independent sample t-test results regarding the life quality scores of amputees according to their marital status were presented in Table 3. It could be seen that the average life quality scores of the married individuals $(\bar{X}=91,15, \mathrm{Ss}=10,70)$ were significantly lower than the scores of the single individuals $(\bar{X}=83,10, \mathrm{Ss}=15,48)(\mathrm{t}$ $\left.{ }_{(193)}=3.902, \mathrm{p}<0.01\right)$.

Table 4. Independent Sample T-test Results regarding the Depression Score Averages of Amputees According to Their Marital Status

\begin{tabular}{|c|c|c|c|c|c|c|}
\hline $\begin{array}{c}\text { Marital } \\
\text { Status }\end{array}$ & $\mathrm{N}$ & $\bar{X}$ & $\mathrm{Ss}$ & $\mathrm{Sd}$ & $\mathrm{T}$ & $\mathrm{p}$ \\
\hline Married & 72 & 8.40 & 7.82 & 193 & 3.964 & $0.001^{*}$ \\
\hline Single & 123 & 13.81 & 9.91 & & & \\
\hline
\end{tabular}

\section{$\mathrm{P}<0.01$}

Independent sample t-test results on depression scores of amputees according to their marital status were presented in Table 4. It was possible to mention that the average depression scores of married individuals $(\bar{X}=8,40, \mathrm{Ss}=7,82)$ were significantly lower than the depression scores of unmarried individuals $(\bar{X}=13,81$, $\mathrm{Ss}=9,91)\left(\mathrm{t}_{(193)}=3.964, \mathrm{p}<0,01\right)$.

Table 5. Kruskal Wallis H-test results regarding the average life quality scores of amputees according to their disabled limbs

\begin{tabular}{|c|c|c|c|c|c|c|}
\hline $\begin{array}{c}\text { Disabled } \\
\text { limb }\end{array}$ & $\mathrm{N}$ & $\begin{array}{c}\text { Order } \\
\text { Average }\end{array}$ & $\mathrm{X}^{2}$ & $\mathrm{Sd}$ & $\mathrm{p}$ & MWU \\
\hline Hand & 7 & 123.14 & 11.315 & 3 & $0.010^{*}$ & \\
\cline { 1 - 5 } Arm & 15 & 136.17 & & & & \multirow{2}{*}{$\begin{array}{c}\text { Arm/leg } \\
\text { Foot/Leg }\end{array}$} \\
\hline Foot & 108 & 105.18 & & & & \\
\hline Leg & 72 & 86.65 & & & & \\
\hline Total & 202 & & & & & \\
\hline
\end{tabular}

$\mathrm{P}<0.05$
Kruskal Wallis H-test was performed for determining whether there was a significant difference in the life quality and depression scores order averages of amputee athletes and the individuals maintaining a sedentary lifestyle according to their disabled limbs. Table 5 presented the results related to whether there was a significant difference between the life quality score order averages of the participants according to their disabled limbs. The Kruskal Wallis $\mathrm{H}$-test results revealed that the difference between the life quality score order averages was significant $\left(\mathrm{X}^{2}=11.315, \mathrm{p}<0,05\right)$. Mann-Whitney $\mathrm{U}$-test was performed to find the source of the difference. Test results showed that there was a significant difference between the average life quality scores of amputees with disabled arms-legs and feet-legs. In reference to these results, it could be said that the leg amputation reduced the life quality more when compared to hand, arm and foot amputation.

Table 6. Kruskal Wallis H-test results on depression level scores order averages of amputees according to their disabled limbs

\begin{tabular}{|c|c|c|c|c|c|c|}
\hline $\begin{array}{c}\text { Disabled } \\
\text { limb }\end{array}$ & $\mathrm{N}$ & $\begin{array}{c}\text { Order } \\
\text { Average }\end{array}$ & $\mathrm{X}^{2}$ & $\mathrm{Sd}$ & $\mathrm{p}$ & MWU \\
\hline Hand & 7 & 109.14 & 10.545 & 3 & $0.014^{*}$ & \\
\cline { 1 - 5 } Arm & 15 & 58.07 & & & & \multirow{2}{*}{$\begin{array}{c}\text { Arm-Foot } \\
\text { Arm-Leg }\end{array}$} \\
\cline { 1 - 5 } Foot & 108 & 100.41 & & & & \\
\cline { 1 - 5 } Leg & 72 & 111.44 & & & & \\
\hline Total & 202 & & & & & \\
\hline
\end{tabular}

$\mathrm{P}<0.05$

Table 6 presented the results of the Kruskal Wallis $\mathrm{H}$-test on the depression level scores order averages of the participants according to their disabled limbs. According to the test results, the difference between depression level scores order averages was significant $\left(X^{2}=10.545\right.$, $\mathrm{p}<0,05)$. It was observed that the significant difference was between the groups with arm-foot amputations and arm-leg amputations. It was found that the depression levels of those with leg and foot amputations were higher.

Table 7. Independent Sample T-test Results Life Quality Score Averages According to Being an Amputee Athlete and Maintaining a Sedentary Lifestyle

\begin{tabular}{|c|c|c|c|c|c|c|}
\hline Status & $\mathrm{N}$ & $\bar{X}$ & $\mathrm{Ss}$ & $\mathrm{Sd}$ & $\mathrm{t}$ & $\mathrm{p}$ \\
\hline Athlete & 76 & 94.46 & 10.52 & 200 & 7.255 & $.000^{*}$ \\
\hline Sedentary & 126 & 80.89 & 14.11 & & & \\
\hline
\end{tabular}
${ }^{*} \mathrm{p}<.01$

Table 7 showed that the difference between the life quality score averages of participants according to being amputee or maintaining a sedentary lifestyle was significant $\left(\mathrm{t}_{(200)}=7.255, \mathrm{p}<\mathrm{p}<0.01\right)$. It could be observed that the scores related to the life quality of the athletes 
$(\bar{X}=94,46$, Ss $=10,52)$ were higher rather than the scores of the individuals maintaining a sedentary lifestyle $(\bar{X}=80,89, \mathrm{Ss}=14,11)$.

Table 8. Independent Sample T-test results on Depression Score Averages According to Being Amputee and Maintaining a Sedentary Lifestyle

\begin{tabular}{|c|c|c|c|c|c|c|}
\hline Status & $\mathrm{N}$ & $\bar{X}$ & $\mathrm{Ss}$ & $\mathrm{Sd}$ & $\mathrm{t}$ & $\mathrm{p}$ \\
\hline Athlete & 76 & 9.50 & 8.15 & 200 & 2.781 & $.000^{*}$ \\
\hline Sedentary & 126 & 13.45 & 10.65 & & & \\
\hline
\end{tabular}

${ }^{*} \mathrm{p}<.01$

Independent sample t-test results for depression score averages of athletes and the individuals maintaining a sedentary lifestyle were shown in Table 8 . The test results indicated that the difference between the depression scores of athletes $(\bar{X}=9,50, \mathrm{Ss}=8,15)$ and the individuals maintaining a sedentary lifestyle $(\bar{X}=13,45, \mathrm{Ss}=10,65)$ was significant $\left(\mathrm{t}_{(200)}=2.781, \mathrm{p}<0.01\right)$.

\section{Discussion and Conclusions}

In this study, the findings regarding whether the life quality scores of amputees who did and did not do sports differed according to some variables were discussed. The research revealed that the total life quality scores of amputee athletes were statistically higher at $p<0.01$ significance level rather than the scores of amputees maintaining a sedentary lifestyle, and depression levels were lower. In other words, as the life quality of amputees who did sports increased, their depression levels decreased.

There was sufficient number of studies in the literature supporting the results of this study. For example, the study by Muraki et al. [16] revealed that depression was low when involvement in sports was high in the patients with spinal cord injuries (169 males). In his study on patients, Güler [17] reported that depression and quality of life were closely related, and physical, emotional and social well-being was also negatively affected in the patients with poor quality of life. Similarly, in their study on American soccer players, Schwenk et al. [18] found that physical mobility, economic situation and social life which were the sub-scales of quality of life were lower in retired professional soccer players exposed to depression; and as retired footballers' level of depression increased, their quality of life scores decreased. Therefore, it was possible to say that depression affected the quality of life, and the quality of life affected depression. It was also possible to mention that emotional reactions of amputees decreased as the duration of sports increased. Indeed, it was possible to reduce the negative effects of amputation which created major physical, psychological and social problems in a person's life through sport. Sport was one of the main social institutions that provided physical fitness as well as identity and promoted participation in social life [19].
A statistically significant difference was found at $p<0.01$ level between total quality of life scores of married and unmarried amputees maintaining a sedentary lifestyle. It was found that the life quality levels of married amputees maintaining a sedentary lifestyle were higher than single individuals. Many studies showed that married individuals had higher quality of life than single and widowed individuals $[20,21,22]$. The study by Peter et al. [23] identified marriage as one of the most important determinants of life quality

There were statistically significant differences (in favor of married amputees) between the depression levels of married and single amputees maintaining a sedentary lifestyle. In their study carried out on the patients diagnosed with cancer, Aydoğan et al. [24] stated that there was no statistically significant difference between depression scores in terms of marital status. In parallel, Baydur [25] did not find any significant difference between the average depression scores of retired professional footballers in terms of their marital status. However, Altay and Üstün [26] found that the marital status of elderly patients in a university hospital affected their depression levels. When the relationship between the marital status of the elderly and the risk of depression was examined, the risk of depression of widowed and divorced old individuals was higher than that of married elderly. This result was in line with the study results on the amputees maintaining a sedentary lifestyle. The depression scores of single and widowed amputees maintaining sedentary lifestyles were found to be higher than the depression scores of married ones.

A significant difference was found between the life quality score order averages of amputee athletes and those maintaining sedentary lifestyles according to their disabled limbs. Considering this finding, it could be said that lower leg amputation affected the life quality of amputees. In their study carried out with 539 people, Demet et al. [27] examined the relationship between upper and lower extremities and quality of life. In this study, those with upper limb amputation were found to have better health-related life quality levels than those with lower limb amputation mostly due to physical disability, pain, and energy level scores. This was in line with the results above. It could be said that the disabilities especially in the lower extremity caused the patients to have more difficulties such as transportation and mobility. According to the results of the Kruskal Wallis H-test on the depression level score order averages according to the disabled limbs of the participants, the difference between the depression level score order averages was significant $(\mathrm{X} 2=10,545, \mathrm{p}<0,05)$. It was observed that the significant difference was between the groups with arm-foot amputations and arm-leg amputations. It was found that those with leg and foot amputations had higher levels of depression than those with hand and arm amputations. It was possible to report that the limitation of the ability of an individual to move himself/ herself 
from one place to another had a negative effect on his/her depression level.

Amputee athletes had significantly higher life quality scores than those maintaining sedentary lifestyles (p $<0,01)$. This showed that amputees' involvement in sports had positive influence on their quality of life. This result obtained from the research was similar to the results of the research in the related literature.

The average depression scores of the amputees maintaining sedentary lifestyles were significantly higher than those of amputee athletes ( $p<0,01)$. It could be said amputees' involvement in sports had a decreasing effect on depression level.

This study in which we examined the quality of life and depression levels of amputees in terms of various variables revealed that the life quality levels of amputee athletes and those maintaining sedentary lifestyles differed in terms of depression scores. The quality of life scores of amputees doing sports was significantly higher than those of amputees maintaining sedentary lifestyles $(\mathrm{p}<0,01)$. Consequently, the depression levels of amputee individuals doing sports were also significantly lower than those of amputees maintaining sedentary lifestyles ( $p$ $<0,01)$. As the level of life quality increased, the level of depression decreased.

While there was no difference between amputee athletes' quality of life and depression levels in terms of their marital status, there was a significant difference between married and single amputees maintaining sedentary lifestyles. While the life quality of married amputees was high, that of single amputees was low. Similarly, the depression levels of married amputees maintaining sedentary lifestyles were significantly lower than those of single ones $(p<0,01)$.

The life quality of amputees who did sports was significantly higher than the life quality of amputees who did not do sports $(p<0,01)$. On the other hand, amputees who did sports had significantly lower levels of depression than those who did not. This study was limited for examining the life quality and depressive status of male amputees in terms of their marital status, doing or not doing sports and limb amputation. This could further be examined in all amputees considering different aspects. Furthermore, because this study was limited only with football as a team sport, it could be examined in terms of other individual and team sports.

In light of all these findings, appropriate sports activities could be given importance to bring the levels of life quality and depression of amputees to the desired levels. Sports facilities for disabled people should be established in every city in Turkey, and regulations can be put into force for the disabled individuals to benefit from existing sports facilities. Amputees' involvement in sports activities can increase their life quality as well as decrease their depression levels.

\section{REFERENCES}

[1] Demirel H, http://www.sbt. hacettepe.edu.tr/index.php?pid= 1444 \&la ng= en\&publish=4\&action=10000 Retrieved on: $13.09,2012$

[2] Esdaile SA, Greenwood KM, A comparison of mothers' and fathers' experience of parenting stress and attributions for parent child interaction outcomes. Occup Ther Int, 10:115-126, 2003.

[3] Miller AC, Gordon RM, Daniele RJ, Stress, appraisal and coping in mothers of disabled and nondisabled children. $\mathrm{J}$ Pediatric Psychology, 17:587-605, 1992.

[4] Özsoy Y, Özyürek M, Eripek S. Children in need of special education, introduction to special education. Ankara, Karatepe Publications. 2002.

[5] Anonymous, Orthopedic Disabilities, Prime Ministry General Directorate of Family and Social Research, Family Education Guide, 2007

[6] Özer S D, Physical education and sports for the disabled. Ankara, Nobel Publication-Distribution.; 4- 21.Ankara, 2001

[7] Santiago M, Coyle C. Leisure-time physical activity and secondary conditions in women with physical disabilities. Disability Rehabilitation, 26(8):485-494, 2004

[8] Van der P loeg, H.P., Streppel, K. R., van der Beek, A.J., van der Woude, L.H., van Harten, W. H., van Mechelen, W. Underlying mechanisms of improving physical activity behavior after rehabilitation. International Journal of Behavioral Medicine, 15 (2), 101-108, 2008

[9] Devine MA, Being a doer instead of a viewer: The role of inclusive leisure contexts in determining social acceptance for people with disabilities. Journal of Leisure Research; 36(2):137-159, 2004

[10] Eichsteadt CB, Lavay BW, Physical Activity for Individuals with mental retardation, Campaign, Illinois, 47,1995

[11] Chiang T, Effects of a therapeutic recreation intervention within a technology-based physical activity context on the social interaction of male youth with autism spectrum disorders, Indiana University, 2003

[12] Köse, E. Scientific Research Models, R. Y. Kıncal (Ed.). Scientific Research Methods (5th Edition) (99-124), Ankara: Nobel Publishing House, Ankara, 2017

[13] Karasar N, Scientific research methods. Nobel Publications, Ankara; 87, 2003

[14] Beck AT, Steer RA, Garbin MG. Psychometric properties of the Beck Depression Inventory: Twenty- five years of evaluation. Clinical Psychology Review; 8:77- 100, 1988

[15] Hisli N. Beck, a study on the validity of the depression scale. Journal of Psychology; 6 (22): 118-126, Izmir, 1989

[16] Fidaner H, Elbi H, F idaner $\mathrm{C}$ and all. Measurement of the Quality of Life, WHOQOL-100 and WHOQOL-BREF. Psikiyatri Psikoloji Psikofarmakoloji Dergisi, 1999, 7:5-13.

[17] Muraki S, Tsunawake N, Hiramatsu S, Yamasaki M. The effect of frequency and ode of sports activity on the psychological status in tetraplegics and paraplegics. Spinal 
Cord; 38(5):309-314, 2000

[18] Güler D, Mastalgia, quality of life and depression. Ministry of Health, Şişli Etfal Training and Research Hospital, Family Medicine, İstanbul, Dissertation, 2006: 64-65

[19] Schwenk TL, Gorenflo DW, Dopp RR, HippleE.depression and pain in retirement Professional football players. Medicine \& Science in Sport \& Exercise; (4) 39: 606-611, 2007

[20] Kirk, D. \& MacPhail, A.. Social positioning and the construction of a youth sports club. International Review for the Sociology of Sport, 38(1), 23-44. Retrieved from http://journals.sagepub.com/doi/abs/10.1177/10126902030 381002, 2003

[21] Topçu S, BölüktaG RP. Examination of Quality of Life in Stroke Patients and the Effect of Social Support on Quality of Life, Yeni Tip Journal, 29(3):159, 12012

[22] Y1ldirım A, "The Importance of Patient Satisfaction and Health-Related Quality of Life After Renal Transplantation", Transplantation Proceedings, 38:2831, 2006

[23] Öğütmen B, Yildirim A, Sever MS, Bozfakioğlu S, Ataman

\footnotetext{
${ }^{\mathrm{i}}$ This study was carried out performing different analyses from the doctoral study conducted by Y. Mehmet in 2012 .
}

R, Erek E, Cetin O. and Emel, A. "Heath-Related Quality of Life After Kidney Transplantation in Comparison Intermittent Hemodialysis, Peritoneal Dialysis and Normal Controls", Transplantation Proceedings ,38:419-421, 2006

[24] Peter K, Warren S, Madill H. Quality of life of stroke survivors. Quality of Life Research; 8:293-301, 1999

[25] Aydoğan Ü, Doğaner YÇ, Borazan E, Kömürcü g, Koçak N, Özet A, Sağlam K, Öztürk B. Relationship between depression and anxiety levels and attitudes to cope with disease of cancer patients, Journal of Turkish Family Practice.;16(2):55,2012

[26] Baydur H., Occupational health and quality of life. 3rd national quality of life health congress, İzmir,; 82-84. 2010

[27] Altay B, Üstün G. Depression Risks in Elderly Patients in a University Hospital and Some Socio-Demographic Characteristics, Acibadem University Journal of Health Sciences Volume: 3, Issue: 2, pp, 108-116 April, 2012

[28] Demet K, Martinet N, Guillemin F, Health related quality of life and related factors in 539 persons with amputation of upper and lower limb. Disabil Rehabil.; 25:480-486, $2003^{1}$ 